\title{
Pedagogy for ethnic minority pupils with special educational needs in
} England

Tan, Andrea; Ware, Jean; Norwich, Brahm

\section{Oxford Review of Education}

DOI:

$10.1080 / 03054985.2017 .1331845$

Published: 01/01/2017

Peer reviewed version

Cyswllt i'r cyhoeddiad / Link to publication

Dyfyniad o'r fersiwn a gyhoeddwyd / Citation for published version (APA):

Tan, A., Ware, J., \& Norwich, B. (2017). Pedagogy for ethnic minority pupils with special educational needs in England: Common yet different? Oxford Review of Education, 13(4), 447461. https://doi.org/10.1080/03054985.2017.1331845

\footnotetext{
Hawliau Cyffredinol / General rights

Copyright and moral rights for the publications made accessible in the public portal are retained by the authors and/or other copyright owners and it is a condition of accessing publications that users recognise and abide by the legal requirements associated with these rights.

- Users may download and print one copy of any publication from the public portal for the purpose of private study or research.

- You may not further distribute the material or use it for any profit-making activity or commercial gain

- You may freely distribute the URL identifying the publication in the public portal ?
}

Take down policy

If you believe that this document breaches copyright please contact us providing details, and we will remove access to the work immediately and investigate your claim. 


\title{
Pedagogy for ethnic minority pupils with special educational needs in England: common yet different?
}

\begin{abstract}
:
The increasing ethnic diversity in the UK has highlighted the importance of supporting primary school pupils with English as an Additional Language (EAL), some of whom also have special educational needs (SEN). However, there is relatively little research carried out in the UK on children with both EAL needs and SEN. This paper presents the results of a study which aimed to explore the strategies used to teach and support pupils with the dual needs in four schools in North-West England. It reports research carried out with 8 EAL pupils with Speech, Language and Communication Needs (SLCN) and 4 pupils with Learning Difficulties (LD) and explores the different strategies staff used to support these pupils. The results showed that the two groups varied in the extent to which staff differentiated pedagogical strategies. The paper concludes by pointing to the need for further training and greater collaboration between the fields of EAL and SEN in research and educational practice.
\end{abstract}

\section{Key words:}

ethnic minority, English as an Additional Language, special educational needs, pedagogy, teaching strategies, speech and language needs, learning difficulties 


\section{Introduction}

With globalization, the populations of cities are becoming increasingly diverse. These changes in population demographics are also manifested in schools, especially those in the cities, which face the challenge of educating children with diverse backgrounds and needs. In the last decade, educational research has increasingly engaged with the challenges of educating pupils with diverse needs, including those from ethnic minority backgrounds or those with learning needs. However, there is a general dearth of literature in the field of support for ethnic minority pupils who also have special educational needs. To understand the importance of this issue, it is helpful to consider its historical background in relation to immigration trends and issues in England and the U.S.

Most of the research on ethnic minority pupils with special educational needs has been carried out in the U.S. With the long history of immigration in the United States, especially the influx of immigrants in the 1990s which saw rapid economic expansion, the population in America has become more diverse (although the demographics differ across different parts of the country). Parents and activists have raised concerns regarding inappropriate educational provision for children who are English language learners (ELLs) such as being taught by staff who have not been trained to work with bilingual learners (Crawford 2008) and the lack of funding and support for bilingual education (McNeil 2009). Some of these concerns have resulted in lawsuits against several school districts in the U.S (McNeil 2009). At the same time, the fight for the educational and linguistic rights of these children has stimulated research in this field. Consequently, the assessment of learning needs and teaching approaches for ELLs and ELLs who also have disabilities have also received some attention, although most of the studies have been carried out in bilingual or special 
education settings in the U.S. (Paneque \& Rodriquez 2009; Santamaría et al. 2002) which are rather different from largely monolingual teaching settings common in British mainstream schools.

In England, the Bullock Report (1975) drew attention to the need to meet the linguistic needs of 'immigrant children' (p.284), some of whose parents came from the West Indies, India, Bangladesh, Pakistan, China, Italy, Spain and Cyprus to work in Britain. While some of these children were born in Britain and their families had lived in Britain for many years, others had just arrived in Britain with their families. The report highlighted the need to meet the linguistic needs of immigrant learners across the various levels of English proficiency, not just new arrivals. It warned against stereotyping the immigrant child, recommending instead that authorities carry out a survey of immigrant children in schools, "distinguishing between their different ethnic origins, identifying their levels of proficiency in English, and making flexible educational arrangements accordingly" (p.284). The report also highlighted the frequent lower attainment levels in reading, especially among children of West Indian origin. In particular, it urged teachers to recognize the Jamaican Creole as a language resource that these students bring with them to the classroom and view their home language positively instead of dismissing it as ‘sloppy’ English (p.287).

In addition, the report pointed out the lack of specialist language teachers who could support second language learners beyond the initial stages of learning English and work with them to advance their fluency in the various language skills. It also hinted at how mistakes by a second language learner might appear similar to the 'slow-learning native speaker' (p.290) and recommended that specialist language teachers work closely with subject staff to address linguistic demands across the curriculum. To address these issues, the report emphasized the 
importance of training and recruiting teachers with the appropriate skills and attitudes necessary to work with ethnic minority children. However, it provided little guidance on the training and support needed to help staff differentiate between ethnic minority children who have linguistic needs arising naturally from their second language learning process and ethnic minority children who have both linguistic needs and learning difficulties. With growing migration in the last 40 years or so following the Bullock Report, the issues highlighted in the report have become more pertinent than ever.

In the past thirty or so years, another area which has been discussed widely in England is that of the educational provision for children with 'special educational needs'. The term 'special educational needs' originated with the Warnock Report of 1978 and the 1981 Education Act and refers to a child with 'a learning difficulty or disability which calls for special educational provision to be made for him or her' (Department for Education 2014, p.19). It does not include children with needs arising from their ethnic backgrounds or family and care circumstances (Department for Education 2014), unlike broader alternative terms adopted in Wales ('additional learning needs') and Scotland ('additional support needs'). In England, following from the publication of the Bullock Report (1975), there has been little guidance regarding how schools can support children from ethnic minority backgrounds who also have special educational needs.

This paper presents the results of a small-scale study conducted with ethnic minority pupils with special educational needs in England. Possible overlaps in pedagogical approaches for these children with dual needs are discussed and implications for practice and training highlighted. 


\section{Current context and review of research in England}

The number of ethnic minority pupils in England has been increasing over the years, and recent official figures indicate that $30.4 \%$ of pupils in state-funded primary schools in England are of ethnic minority origin (Department for Education 2015a). One in five (19.4\%) state-funded primary school pupils has a first language other than English. These pupils are commonly referred to as EAL pupils as they are learning English as an Additional Language (EAL).

At the same time, the current policy in the UK is geared towards educating children with special needs in mainstream schools (Warnock \& Norwich 2010). Official figures from 2015 suggest that $14.4 \%$ of primary school pupils have identified special educational needs (SEN) with an Education, Health and Care plan or are on SEN support (Department for Education 2015b). 15\% of pupils in state-funded primary schools in England whose first language is other than English are identified with SEN (Department for Education 2015b). Although little information is available on their proficiency in English from the census, it is likely that some of these pupils will have dual needs due to language/cultural differences and special educational needs.

The research on ethnic minority pupils with special educational needs in the UK has largely focused on issues of identification, with discussion suggesting both underidentification and over-identification. Lindsay et al. (2006) point out that schools, local authorities and professionals may either under- or over-estimate the nature and severity of the learning needs of EAL pupils. Pupils from particular ethnic groups were reported to be either more likely or less likely to have SEN than other ethnic groups (Department for Education 
2012). For example, Black pupils were more likely to be identified with SEN and Chinese pupils less likely to be identified with SEN than pupils from other ethnic minority backgrounds. Possible reasons for the discrepancy of the proportion of learners identified with SEN from the various ethnic groups are teachers' perceptions and understanding of different cultures, lower utilisation of healthcare services among some ethnic groups and problems in distinguishing learning difficulties from EAL (Lindsay et al. 2006; Frederickson \& Cline 2015). Also, the identification process could be complicated by the fact that little is known about ethnic differences and their implications for learning whereas there is relatively more understanding regarding some medical conditions relevant to SEN (e.g. cerebral palsy).

Government guidance documents make little mention of pedagogical principles to support ethnic minority pupils with special needs. For example, the SEND Code of Practice 2014 (Department for Education \& Department of Health 2014) emphasised the need for "high quality teaching, differentiated for individual pupils" (p.99). However, it is not clear what is meant by 'high quality teaching' and how teaching should be differentiated, especially with reference to pupils with dual needs in both EAL and SEN.

Very little research has been carried out in the UK focusing on pedagogies to support ethnic minority pupils who have special educational needs. In one case study of a school which had a relatively high proportion (40\%) of EAL learners, Fergusson and Duffield (2003) discussed how this special school in East England worked with the bilingual assistants and parents to support EAL pupils with Profound and Multiple Learning Difficulties (PMLD). 
I CAN (2011) examined the evidence base of interventions used by specialists and school staff to support children with speech and language difficulties in the UK. Of 61 interventions reviewed, only one was used with children who have both EAL and language delay needs. Evaluation of the 10-week Talk Boost intervention conducted across 12 primary schools found that children with both EAL and language delay made significant progress in terms of their language and communication skills compared to the group of children who received no intervention, although it was not clear whether it was as a direct result of the intervention as there was no control EAL group that did not receive the intervention (I CAN 2011).

Secondary research has highlighted the importance of using pedagogy which is relevant to all learners while recognizing the need for differentiation for some groups of learners (Martin 2005; Hartas 2005; Ravet 2011). However, the delineation of group-specific strategies (Hartas 2005) is not clear and empirical support is often lacking. The paucity of research in this area is perhaps unsurprising as support for children with EAL or SEN has been traditionally associated with either EAL pedagogy or SEN pedagogy, with the research and guidance in these two fields being kept generally distinct.

\section{Research aims}

The study examined strategies used to teach and support pupils with the dual needs of EAL and SEN in four mainstream primary schools in England. It also explored possible factors influencing the use of strategies. After a preliminary analysis of data collected on 21 children with both EAL and SEN in the four schools, a decision was made to focus the analysis on two main groups of children at the schools (EAL pupils with speech, language 
and communication needs, EAL pupils with learning difficulties) as it was felt that concentrating the analysis on groups of children with similar needs within each group would strengthen the reliability of the findings. This paper specifically addresses the following question:

What strategies do the staff use to teach/support pupils with EAL and SEN?

(i) Are the strategies specific to the children with dual needs or are they also used to support the whole class or other groups of children in the class?

(ii) In what ways are the strategies used to support SEN groups with more clearly defined identities (e.g. speech, language and communication needs) similar or different to groups with less distinct identities (e.g. learning difficulties)?

The term "staff" is used in a broad sense here and refers to all professionals involved in the teaching or support of the children at school. This includes teachers, teaching assistants, bilingual assistants, speech and language therapists, SEN and EAL Coordinators.

The pupils in the study reported here comprised two groups: 8 EAL pupils with Speech, Language and Communication Needs (SLCN) and 4 pupils with Learning Difficulties (LD). The 8 EAL pupils with SLCN were from three schools (Schools A, C, and D) in two cities and the 4 EAL pupils with LD were from three schools (Schools A, B, and C) in the same two cities. The terms "EAL/SLCN" and "EAL/LD" are used here and refers to EAL pupils with SLCN or LD. The Department for Education and Skills (2003) defines SLCN as follows: 
"Pupils with speech, language and communication needs may have difficulty in understanding and/or making others understand information conveyed through spoken language. Their acquisition of speech and their oral language skills may be significantly behind their peers. Their speech may be poor or unintelligible. Pupils with speech difficulties may experience problems in articulation and the production of speech sounds. They may have a severe stammer."

(DfES 2003, p.5)

The nature of speech, language and communication needs (SLCN) is different in every child (Hartshorne et al. 2011). Some children have SLCN as their primary need while others experience SLCN with other conditions such as sensory impairments, autism or cerebral palsy (Gascoigne 2012).

The eight EAL children in this study were identified by their schools as having SLCN as their primary need. Four of them were placed in the SLCN unit in a mainstream school, one in a mainstream classroom in the same school, and three others were in mainstream classrooms in two other schools. Of the eight children, six were reported by staff as having language and communication difficulties. Staff supporting the other two children expressed doubts as to whether they had SLCN as they felt that their difficulties could be difficulties experienced by EAL learners as part of the process of learning a second language. One of the children had joined the school (School C) about half a year ago. She had an Individual Education Plan (IEP) from her previous school and had assessment sessions with a speech and language therapist. Another child had also joined his school (School D) a few 
months ago. His IEP was not available as the Deputy Headteacher said that his teacher was still working on it. Staff supporting these two children were unsure if their difficulties were related to EAL learner needs or SLCN. However, it is possible that the early timing of the research (conducted in the first quarter of the academic year) might mean that staff were still getting to know their new pupils in class, thus explaining the uncertainty.

The second group was a group of four EAL pupils with Learning Difficulties (LD). The term 'learning difficulties' is used here to refer to pupils with moderate learning difficulty. DfES (2003) provided the following definition of moderate learning difficulty:

"Pupils with moderate learning difficulties will have attainments significantly below expected levels in most areas of the curriculum, despite appropriate interventions. Their needs will not be able to be met by normal differentiation and the flexibilities of the National Curriculum. Pupils with moderate learning difficulties have much greater difficulty than their peers in acquiring basic literacy and numeracy skills and in understanding concepts. They may also have associated speech and language delay, low self-esteem, low levels of concentration and under-developed social skills."

(DfES 2003, p.3)

Various authors have highlighted how the identification and definition of this group is rather nebulous (Norwich \& Lewis 2001; Fletcher-Campbell 2005). The four EAL pupils involved in this study were identified by their schools as having moderate learning difficulties as their main/only need. They were placed in mainstream classrooms in three 
schools. As discussed in the literature, there is no clear definition of the group of learners with 'moderate learning difficulty', so it is perhaps unsurprising that opinions regarding the pupils' needs varied among the staff in spite of the fact that all the pupils were recorded in their school registers as having LD. Some teachers and assistants described the pupils in the study as having "low ability" or "delayed" in their learning, lacking concentration, and requiring help with social interaction. However, it is interesting to note that most staff members did not view these pupils as having special educational needs although they felt that they needed some help with their learning and interaction in class.

\section{School profiles}

The study was conducted in four mainstream schools in two cities in North West England (thereafter referred to as City Alpha and City Omega). Schools A and B were in City Alpha, and Schools C and D were in City Omega. One of the schools (School A) had a SLCN unit. Brief profiles of the four schools are presented in Table 1:

\section{Insert Table 1 about here}

The study examined the strategies used to teach and support pupils with EAL/SLCN and EAL/LD. The 8 EAL/SLCN pupils were from three schools (Schools A, C, and D), and the 4 EAL pupils/LD were from three schools (Schools A, B, and C). As shown in Table 1, Schools A and B had a higher proportion of learners with SEN than EAL. Both schools were also equipped with facilities and resources to support pupils with SEN (e.g. a speech and language therapist who worked regularly with the SLCN unit in School A and facilities

supporting children with severe needs in School B). In contrast, Schools C and D had a higher proportion of learners with EAL than SEN. School D also had a bilingual teaching 
assistant who supported the Polish-speaking children in the school. Through involving schools with varied profiles, this study offers insight into the strategies used across different types of mainstream schools.

\section{Pupil profiles}

The study was conducted using a case study approach with mixed data collection and analysis methods. Each case was defined as the kind of support given to children with similar needs in the same classroom setting. For example, the support given to four EAL pupils with SLCN who were in the same SLCN unit class in School A (AP1-AP4) constituted one case. There were a total of eight cases in the study.

Table 2 provides a brief summary of the cases, four in the EAL/SLCN group and four in the EAL/LD group.

\section{Insert Table 2 about here}

The contrasting profiles of the two groups (EAL/SLCN and EAL/LD) provided the conditions for theoretical replication where the findings of specific/general pedagogies for EAL children with SLCN could be compared to the findings for EAL children with LD. Within each group, there were four cases from a variety of schools and year groups. As indicated in Table 2, in some cases, there was no common or clear understanding of the children's home languages or nature of SEN. 


\section{Data collection and analysis}

The case study involved lesson observations, staff and pupil interviews, field notes, photographs and documents concerning individual pupils (e.g. Individual Education Plans, assessment reports by Speech and Language therapists).

The similarities and differences in strategies used for the two groups were analysed, culminating in a model which presents (i) the common strategies used to support both groups and (ii) the strategies unique to each group. As part of further analysis, the common strategies used to support children in both groups were examined in detail and themes were identified in terms of how these strategies were used to support the two groups.

\section{Strategies used to teach or support the pupils}

Preliminary analysis of strategies used to teach/support pupils with EAL and SLCN or LD was conducted on eight cases. A total of 14 main strategies were identified to have been used to teach/support the children. This means that these strategies were mentioned in several staff interviews and/or observed in multiple instances in the lessons. The classification of the

strategies used in this study was derived from a) review of the literature and b) staff interviews.

[Insert Table 3 about here.]

As shown in Table 3, six of the strategies have been used by staff to teach and support EAL children with either SLCN or LD. These six strategies (common to both groups) were analysed further in terms of their sub-strategies and contexts in which they were used. As part 
of the analysis, strategies were constantly compared and contrasted for any links between them, taking into consideration the insights and rationale provided by the staff interviews and contexts of the lesson observations. Strategies which were similar in terms of function and context were classified as "sub-strategies" under a main strategy. Each of these 6 common main strategies was supported by various sub-strategies listed in Table 4.

\section{[Insert Table 4 about here.]}

Most strategies in the literature on teaching children with EAL and SEN have been used to support the children in the study as sub-strategies. As mentioned earlier, the research literature comes mainly from the U.S. where the settings are bilingual or in special education provision.

The strategies from the literature which emerged in the study include providing opportunities for oral language development (Grassi \& Barker 2010; Garcia \& Tyler 2010), making links to pupils' daily lives and experiences (Roseberry-McKibbin 2007; Fergusson \& Duffield 2003), explicitly teaching key terms in the topic (Shyyan et al. 2008; Echevarria \& Graves 2007), using the pupils' home languages in instruction or allowing support in the home languages from bilingual assistants or peers (Paneque \& Rodriguez 2009; Leicester City Council \& Children's Community Health Service (NHS) 2011), giving explicit and clear instructions (Gross 2002), using visual aids and pictures (Rodriguez 2009), checking pupils' understanding of the topic and instructions (Hartas 2005), using simpler speech and gestures (Hart 2009), conducting demonstrations (Brice \& Perkins 1997) and increasing wait time (Hart 2009). With the exception of the use of the pupils' home languages, these seem to be 
generic strategies which could be used to support children who needed more help with their learning.

Most of the strategies in the literature were employed as sub-strategies in this study. For example, "conducting demonstrations" was used as a sub-strategy to provide "comprehensible input" (main strategy) to the children, alongside other sub-strategies such as "using visual aids" which were aimed at helping pupils understand the topics better.

The only exception was the strategy "using the child's first language" which emerged as one of the 14 main strategies as it was a main strategy used in one of the EAL/SLCN case studies. Several instances of the strategy were observed in the lessons and all staff members who were interviewed highlighted it as a strategy which they used to support the children who had Polish as a first language. There was also a bilingual assistant in the school who helped to explain matters in Polish to the children whenever there was a behavioral issue.

The study points to the possible addition of key strategies to the existing research literature. These additional strategies include those which aimed to cater to the attentional and socio-emotional needs of the pupils, namely "keeping the child's attention", "building the child's confidence" and "responding to the child's call for attention/help". For example, the strategy "keeping the child's attention" was employed in two cases through a variety of substrategies such as asking questions to link a story to daily lives, directly instructing the child to pay attention and participate in the class activities, and asking questions to check on the child's understanding of the story. 
Similarities and differences in the case studies are presented in the form of a model in Figure 1. 


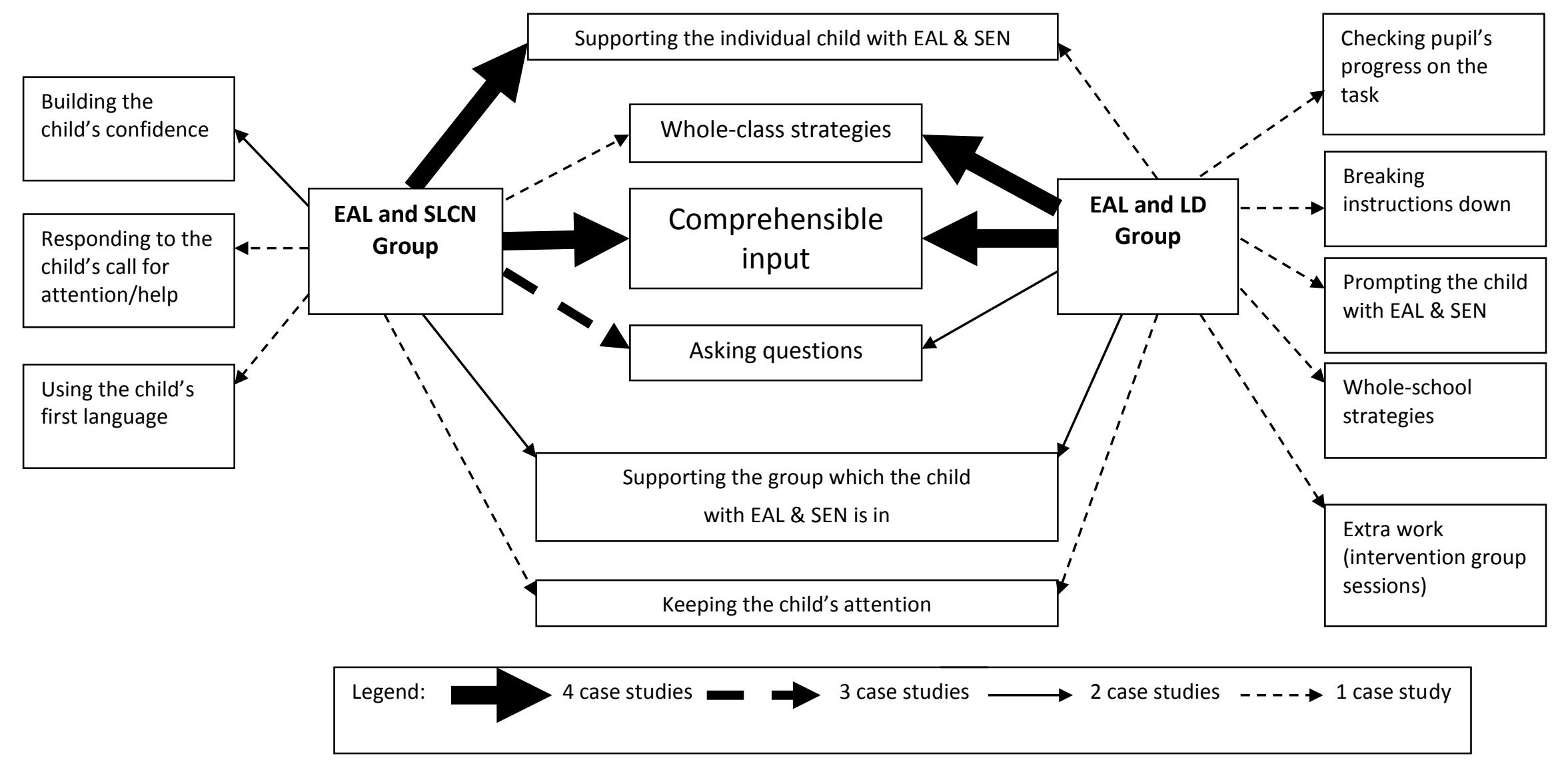

Figure 1 Overall model of strategies used to support children with EAL and SLCN/LD 
Figure 1 illustrates the strategies which are common to both groups and those specific to each of the groups. It is noteworthy that the prevalence of the strategies differs across the case studies, as indicated by the coding of the arrows.

\section{Language-focused vs Task-focused strategies}

An in-depth analysis of the six strategies which are common to both groups has also revealed some differences in the types of strategies and the ways these strategies have been used for both groups. Staff working in the EAL/SLCN group used more of language-focused strategies and provided individual/group support whereas staff working in the EAL/LD group used more of task-focused strategies and provided support at the class level. The difference in the types of sub-strategies was demonstrated in the analysis of the following strategies:
(a) Asking questions
(b) Comprehensible input
(c) Supporting the individual child with EAL and SEN

For example, the strategy "asking questions" was used for different purposes in the two groups of case studies. Staff working with the EAL/SLCN group used the strategy for more language-related purposes (to elicit discussion / develop oral communication skills and build vocabulary) whereas staff working with the EAL/LD group used the same strategy for more task-related purposes (to check pupil's understanding of task instructions and check if pupil needs help with task). 
The findings are in line with reviews given by SEN experts in Lewis and Norwich (2005). Groups which have a less clearly defined identity (e.g. moderate learning difficulties) seem to be associated with more general pedagogies (or what is called the 'unique differences position') whereas groups with a more clearly defined identity such as autistic spectrum disorder tend to be associated with more specific pedagogies ('general differences position'). Martin (2005) argued for 'a common pedagogic approach' which integrates language and learning, taking into account the commonalities in terms of learning needs in EAL and SLCN (p.106). The findings of this study seem to lend support to this argument as EAL children with SLCN were supported with strategies which were language-focused whereas EAL children with LD were supported with more task-focused strategies.

\section{More differentiation in EAL/SLCN group}

Some strategies were applied using a more differentiated approach by the staff supporting the EAL/SLCN group than those supporting the EAL/LD group. For instance, EAL/SLCN staff used the strategy of asking questions with a greater variety of follow-up responses compared to the EAL/LD staff (see Table 5).

\section{Insert Table 5 about here}

The greater variety of follow-up responses across the EAL/SLCN group (AP1-AP4; CP4; DP1 and DP4) seems to be in line with the EAL/SLCN staff interviews which indicated that the strategy of asking questions was applied using a more differentiated approach. For instance, the following excerpt from CT4's interview (teacher of CP4) highlights the importance of changing one's questioning according to the ability of the individual or group. 


\section{$\underline{\text { C Teacher } 4}$}

"You've got to really change [emphasis] your questioning to match the ability of the group and that can be quite a challenge sometimes. Especially if you have, you know, sort of an overarching theme to get through and get across to them. It's how you do that and how you question and pre-empt what their [emphasis] responses will be as well [softly] can be quite tricky. [softly] ... (later in the interview) I might ask the class a question in one way [emphasis] and then have to change the language or the vocab depending on, you know, if it's direct, who it's directed at. [softly] But sometimes it will have to be said in a different way for CP4 and (name of a boy in the same group who is also an EAL learner) [softly]."

Similarly, a greater variety of sub-strategies was observed in the SLCN group for the

strategies "keeping the child's attention", "supporting the individual child with EAL and SEN" and "supporting the group which the child with EAL and SEN is in", some of which focused on developing the child's language through participation and discussion, encouraging the child and engaging the child through asking questions. It seems that children with EAL and SLCN were supported with a wider range of strategies than children with EAL and LD, suggesting perhaps the need for a more nuanced and differentiated approach in supporting the latter group.

Ravet (2011) cautions that dismissing special pedagogies and adopting a 'common-toall' approach "could simply return children on the (autistic) spectrum to the plight they are only just beginning to emerge from" (p.677) as teachers are not aware of the implications of their needs and how they might affect teaching and learning. Although the caveat was with reference to learners with autism, it is possible that the same consequence could apply to learners with LD if they were not supported using a more nuanced approach which takes into account their range of needs. 


\section{Expanding pedagogic needs}

Seven out of 21 staff members in the EAL/SLCN and EAL/LD groups believed that there was an overlap in EAL needs and SEN. Of these, four felt that there are aspects of EAL needs which are similar to certain types of special needs (SLCN, LD or severe physical needs) while three saw similarity in pedagogical approaches for EAL and SEN in general.

Six members of staff believed in group-specific pedagogy which is relevant to only EAL learners. However, only the EAL Coordinator (DE) highlighted the importance of group-specific approaches relevant to only specific groups of EAL learners such as EAL children who are new arrivals or in Key Stage 2. To DE, the activities differed accordingly depending on the level of English language proficiency and age of the pupils. This is in line with the recent literature and guidance which calls for a need to cater to the diverse English proficiency levels and needs of EAL learners in the UK (Strand \& Lindsay 2012). However, it is striking that children with EAL needs seemed to be largely perceived by the staff as a homogenous group which require pedagogy specific to them as a single group. In addition, most staff members made little mention of the children's home languages which could be used as a resource to aid learning. In some cases, teachers were unsure of the children's home languages.

\section{Specialised vs Generic strategies}

Most of the strategies mentioned by staff participants in the study seemed to be quite generic in nature and could possibly be used to support children in general. The only strategies which seemed more specialised were perceived by staff to be appropriate 
specifically for EAL pupils or pupils with SLCN. For example, staff (DT1 and DA1) used simple words in the home language to instruct and praise the children in their class where many were learning English as an Additional Language.

It might be the case that there are needs specific to a particular group and/or groups of learners but the appropriate pedagogies to meet those needs have not been developed fully and staff are using pedagogies which are more generic in nature. In this study, staff in the EAL/LD group had received little specialised training on pedagogy to support learners with LD or EAL. Moreover, the fact that most staff members in the EAL/LD group did not view their pupils as having special educational needs (but needing some support in their learning) could also have influenced them to adopt more generic strategies. Furthermore, as discussed earlier, a review of research in the areas of EAL and SEN has found that most strategies used or recommended in previous studies were generic in nature. It could be that the current small pool of research has yet to discover group-specific ways to support learners with dual needs.

\section{Implications and recommendations}

There are a number of implications of this small-scale study which might merit presentation in the form of recommendations. First, greater collaboration is needed between focus on EAL and SEN in both research and practice. This study has provided some evidence for perceived commonality between strategies used to support EAL pupils and pupils with SLCN/LD/SEN (in general). While not assuming that group-specific pedagogy is necessarily useful for all other learners, exploring commonality in approaches for EAL learners and other groups of learners could potentially help to bring about more efficient planning and use of resources. 
In addition, the results also suggest particularity in approaches for children with EAL or SLCN among some staff in the EAL/SLCN group. They perceive some pedagogical approaches to be specific only to learners with EAL or SLCN. Greater collaboration between the fields of EAL and SEN in terms of research and practice in schools would help to further the understanding of pedagogies used for pupils with EAL and SEN, both in terms of their commonality and particularity.

A second suggestion is the development of more training with specialism in EAL and LD. It is interesting that in this study, children with EAL and SLCN were supported with a wider range of strategies than children with EAL and LD. Staff supporting the former group employed more language-focused strategies whereas staff supporting the latter group employed more task-focused strategies. This could possibly be linked to the fact that staff members in the EAL/SLCN group generally had more training and experience supporting EAL learners than staff in the EAL/LD group. Also, some members in the former group (the speech and language therapist and speech therapy assistant) received specialist training in speech and language needs. On the other hand, only one teacher in the EAL/LD group reported being trained on supporting children with learning difficulties. There was also no clear understanding about the identity of the group of learners with LD, as reflected in most staff members' perception that their pupils did not have special educational needs and needed only a little support. The findings of this study call for more training on the two areas of EAL and LD for mainstream teachers. 


\section{Conclusions}

This paper has discussed the results of a study involving EAL pupils with SLCN or LD in four mainstream primary schools in England. It is one of the few studies in the UK which has explored the strategies used to teach and support pupils with the dual needs. The findings suggest that while there were some common strategies used to support the two groups, differences were also noted in the types and range of strategies used to support these learners. Staff supporting the EAL/SLCN group used strategies which were more languagefocused whereas those supporting the EAL/LD group used more task-focused strategies. In addition, staff working with the EAL/SLCN group differentiated their strategies to a larger extent than the EAL/LD group. These results, considered in conjunction with staff perceptions, raise some interesting questions regarding the extent to which EAL strategies are similar to SLCN/LD/SEN (in general). The study also points to the need for greater training in EAL and LD. It is possible that the training might help staff to obtain a better understanding of LD and how it is different from EAL learner needs, and in turn influence the strategies adopted to support these learners.

\section{$\underline{\text { References }}$}

BRICE, A. and PERKINS, C. (1997). What is required for transition from the ESL classroom to the general education classroom? A case study of two classrooms. Journal of Children's Communication Development, 19(1), pp. 13-22.

BULLOCK, A. (1975). A language for life: Report of the Committee of Enquiry appointed by the Secretary of State for Education and Science under the Chairmanship of Sir Alan Bullock FBA. London: Her Majesty's Stationery Office. 
CRAWFORD, J. (2008). An equity agenda for English language learners: Beyond Proposition 227 and NCLB. Keynote presentation at the Proposition 227 and Beyond: Connecting Research, Policy, and Practice conference, 7-8 November, San Marcos, CA.

DEPARTMENT FOR EDUCATION (2015a). Schools, pupils and their characteristics: January 2015. SFR 16/2015. London: Department for Education.

DEPARTMENT FOR EDUCATION (2015b). Special Educational Needs in England: January 2015 National Tables. SFR25/2015. London: Department for Education.

DEPARTMENT FOR EDUCATION (2014). Children and Families Act. London: The Stationery Office.

DEPARTMENT FOR EDUCATION (2012). Children with special educational needs: An analysis. SFR24/2012. Department for Education: London.

DEPARTMENT FOR EDUCATION AND SKILLS (2003). Data Collection by Type of Special Educational Need. London: Her Majesty's Stationery Office.

DEPARTMENT FOR EDUCATION and DEPARTMENT OF HEALTH (2014). Special educational needs and disability code of practice: 0 to 25 years. DFE-00205-2013. London: Her Majesty's Stationery Office.

ECHEVARRIA, J. and GRAVES, A. (2007). Sheltered content instruction: Teaching English language learners with diverse abilities. 3rd edn. Boston: Pearson.

FERGUSSON, A. and DUFFIELD, T. (2003). Multicultural inclusion for pupils with severe or profound and multiple learning difficulties. In: C. TILSTONE and R. ROSE, eds, Strategies to promote inclusive practice. London: Routledge Falmer, pp. 34-47. 
FLETCHER-CAMPBELL, F. (2005). Moderate learning difficulties. In: A.LEWIS and B.NORWICH, eds, Special Teaching For Special Children? Pedagogies for inclusion. Berkshire: Open University Press, pp. 180-191.

FREDERICKSON, N. and CLINE, T. (2015). Special educational needs, inclusion and diversity. 3rd edn. Berkshire, England: Open University Press.

GASCOIGNE, M.T. (2012). Better Communication: Shaping speech, language and communication services for children and young people. London: Royal College of Speech and Language Therapists.

GARCIA, S.B. and TYLER, S. (2010). Meeting the Needs of English Language Learners With Learning Disabilities in the General Curriculum. Theory Into Practice, 49(2), pp. 113-120.

GRASSI, E. and BARKER, H.B. (2010). Culturally and Linguistically Diverse Exceptional Students: Strategies for Teaching and Assessment. Thousand Oaks, California: Sage Publications.

GROSS, J. (2002). Special Educational Needs in the Primary School: A Practical Guide. 3rd edn. Buckingham: Open University Press.

HART, J.E. (2009). Strategies for culturally and linguistically diverse students with special needs. Preventing School Failure, 53(3), pp. 197-206.

HARTAS, D. (2005). Language and Communication Difficulties. London: Continuum International Publishing Group.

HARTSHORNE, M., CROSS, M. and BURNS, M. (2011). Misunderstood: Supporting children and young people with speech, language and communication needs. $2^{\text {nd }}$ edn. London: The Communication Trust.

I CAN (2011). Talk Boost Interim report: The development phase. I CAN. 
LEICESTER CITY COUNCIL and CHILDREN'S COMMUNITY HEALTH SERVICE (NHS)

(2011). Meeting individual needs: Speech, Language and Communication Needs - A Good Practice

Guide.

LEWIS, A. and NORWICH, B. (2005). Special Teaching for Special Children? Pedagogies for Inclusion. Maidenhead: McGraw-Hill Education.

LINDSAY, G., PATHER, S. and STRAND, S. (2006). Special Educational Needs and Ethnicity: Issues of Over- and Under-representation. DfES Research Report No. 757. London: DfES

MARTIN, D. (2005). English as an additional language and children with speech, language and communication needs. In: A. LEWIS and B. NORWICH, eds, Special Teaching For Special Children? Pedagogies for inclusion. Berkshire: Open University Press, pp. 96-109.

MCNEIL, M. (2009). Funding disparities squeeze ELL efforts. Education Week, 28(17), pp. 41-43.

NORWICH, B. and LEWIS, A. (2001). A critical review of evidence concerning teaching strategies for pupils with special educational needs. British Educational Research Journal, 27(3), pp. 313-329.

PANEQUE.O.M. and RODRIGUEZ, D. (2009). Language Use By Bilingual Special Educators Of English Language Learners With Disabilities. International Journal of Special Education, 24(3), pp. 63-69.

RAVET, J. (2011). Inclusive/exclusive? Contradictory perspectives on autism and inclusion: the case for an integrative position. International Journal of Inclusive Education, 15(6), pp. 667-682.

RODRIGUEZ, D. (2009). Meeting the Needs of English Language Learners With Disabilities in Urban Settings. Urban Education, 44(4), pp. 452-464.

ROSEBERRY-MCKIBBIN, C. (2007). Language Disorders in Children: A Multicultural and Case Perspective. Boston: Pearson Education. 
SANTAMARÍA, L.J., FLETCHER, T.V. and BOS, C.S. (2002). Effective Pedagogy for English Language Learners in Inclusive Classrooms. In: A.J. ARTILES and A.A. ORTIZ, eds, English Language Learners With Special Education Needs. Washington, DC: Center for Applied Linguistics and Delta Systems Co., pp. 133-157.

SHYYAN, V., THURLOW, M.L. and LIU, K.K. (2008). Instructional Strategies for Improving Achievement in Reading, Mathematics, and Science for English Language Learners With Disabilities. Assessment for Effective Intervention, 33(3), pp. 145-155.

STRAND, S. and LINDSAY, G. (2012). Ethnic disproportionality in the identification of speech language and communication needs (SLCN) and autistic spectrum disorders (ASD): 2005-2011. DFERR247-BCRP15. London: Department for Education.

WARNOCK, M. and NORWICH, B., eds (2010). Special Educational Needs: A New Look 2nd edn. London: Continuum International Publishing Group.

Table 1 Profiles of schools in the study

\begin{tabular}{|l|l|l|l|l|}
\hline School & Enrolment & $\begin{array}{l}\text { Proportion of } \\
\text { EAL learners }\end{array}$ & $\begin{array}{l}\text { Proportion of } \\
\text { learners with } \\
\text { SEN }\end{array}$ & Other comments \\
\hline A & 273 & $10.8 \%$ & $28.2 \%$ & $\begin{array}{l}\text { Had SLCN unit; } \\
\text { Judged to be an } \\
\text { outstanding school by } \\
\text { Ofsted (UK's education } \\
\text { department) for good } \\
\text { practice in inclusion }\end{array}$ \\
\hline B & 244 & $8.5 \%$ & $26.6 \%$ & $\begin{array}{l}\text { Had facilities } \\
\text { supporting children } \\
\text { with physical and } \\
\text { severe needs }\end{array}$ \\
\hline C & 181 & $27.3 \%$ & $9.4 \%$ & $\begin{array}{l}\text { Had bilingual teaching } \\
\text { assistant }\end{array}$ \\
\hline D & 241 & $17.0 \%$ & $9.5 \%$ & \\
\hline
\end{tabular}


Table 2 Profiles of pupils with EAL and SLCN/LD in the study

\begin{tabular}{|c|c|c|}
\hline Pupils & $\begin{array}{l}\text { Home language } \\
\text { (according to the SENCO, } \\
\text { speech and language therapists, } \\
\text { teachers and assistants) }\end{array}$ & $\begin{array}{l}\text { Main or only SEN } \\
\text { (according to the SENCO, } \\
\text { teachers and assistants) }\end{array}$ \\
\hline \multicolumn{3}{|c|}{ EAL/SLCN group } \\
\hline AP1-AP4 & $\begin{array}{l}\text { AP1: Arabic } \\
\text { AP2: Madingo } \\
\text { AP3 and AP4 (twins): } \\
\text { Polish/English/Farsi? }\end{array}$ & SLCN \\
\hline AP7 & Polish/Russian? & SLCN \\
\hline $\mathrm{CP} 4$ & Farsi & $\begin{array}{l}\text { SLCN (Teacher and assistant } \\
\text { felt that she had EAL needs, not } \\
\text { SEN.) }\end{array}$ \\
\hline DP1 and DP4 & Polish & $\begin{array}{l}\text { SLCN (Teacher was unsure if } \\
\text { DP1 had SLCN or EAL learner } \\
\text { needs.) }\end{array}$ \\
\hline \multicolumn{3}{|c|}{ EAL/LD group } \\
\hline AP8 & $\begin{array}{l}\text { Arabic/did not know his home language/ } \\
\text { did not know he was an EAL learner? }\end{array}$ & $\begin{array}{l}\text { LD (Teacher and assistant did } \\
\text { not know that he was on the } \\
\text { SEN register, just 'low ability') }\end{array}$ \\
\hline $\mathrm{BP} 2$ & Did not know his home language & $\begin{array}{l}\text { LD (Assistants felt that he did } \\
\text { not have LD, he just needed } \\
\text { help with social interaction) }\end{array}$ \\
\hline BP3 & Punjabi & $\begin{array}{l}\text { LD (Part-time teacher felt that } \\
\text { he did not have LD, he was just } \\
\text { "delayed" in learning) }\end{array}$ \\
\hline $\mathrm{CP} 2$ & French & $\begin{array}{l}\text { LD (Teacher unsure of his SEN, } \\
\text { he was not really on task) }\end{array}$ \\
\hline
\end{tabular}

\footnotetext{
? The staff gave different answers.
} 
Table 3 Main strategies used to teach and support pupils with EAL/SLCN or

\section{EAL/LD}

\begin{tabular}{|l|c|c|}
\hline Main Strategies & EAL/SLCN group & EAL /LD group \\
\hline Comprehensible input & $\checkmark$ & $\checkmark$ \\
\hline Whole-class strategies & $\checkmark$ & $\checkmark$ \\
\hline Asking questions & $\checkmark$ & $\checkmark$ \\
\hline Supporting the individual child with EAL \& SEN & $\checkmark$ & $\checkmark$ \\
\hline $\begin{array}{l}\text { Supporting the group which the child with EAL \& } \\
\text { SEN is in }\end{array}$ & $\checkmark$ & \\
\hline Keeping the child's attention & $\checkmark$ & $\checkmark$ \\
\hline Building the child's confidence & $\checkmark$ & \\
\hline Responding to the child's call for attention/help & $\checkmark$ & \\
\hline Using the child's first language & $\checkmark$ & $\checkmark$ \\
\hline Checking pupil's progress on the task & & $\checkmark$ \\
\hline Breaking instructions down & & $\checkmark$ \\
\hline Prompting the child with EAL and SEN & & $\checkmark$ \\
\hline Whole-school strategies & & \\
\hline Extra work (intervention group sessions) & & \\
\hline
\end{tabular}

Table 4 Six common strategies and sub-strategies

\begin{tabular}{|l|l|}
\hline Common main strategies & Examples of sub-strategies \\
\hline Comprehensible input & $\begin{array}{l}\text { Teacher-led discussion of vocabulary, } \\
\text { explaining and conducting task } \\
\text { demonstrations to groups, modeling good } \\
\text { language, using visual aids, explaining new } \\
\text { words }\end{array}$ \\
\hline Whole-class strategies & $\begin{array}{l}\text { Encouraging class discussion, using concrete } \\
\text { objects or visuals in class teaching, obtaining } \\
\text { class feedback by asking pupils to put their } \\
\text { thumbs up/down to indicate understanding, } \\
\text { conducting demonstrations of how to } \\
\text { complete the task to all pupils in each group }\end{array}$ \\
\hline Asking questions & $\begin{array}{l}\text { Asking questions for discussion and } \\
\text { development of oral communication skills, } \\
\text { build vocabulary, check comprehension of } \\
\text { concepts and understanding of task } \\
\text { instructions }\end{array}$ \\
\hline $\begin{array}{l}\text { Supporting the individual child with EAL } \\
\text { \& SEN }\end{array}$ & $\begin{array}{l}\text { Creating opportunities for child's } \\
\text { participation in oral activities, use of home } \\
\text { language to explain unacceptable behavior or } \\
\text { praise the child, checking pupil's }\end{array}$ \\
\hline
\end{tabular}




\begin{tabular}{|l|l|}
\hline & $\begin{array}{l}\text { understanding of own reading by asking } \\
\text { questions }\end{array}$ \\
\hline $\begin{array}{l}\text { Supporting the group which the child } \\
\text { with EAL \& SEN is in }\end{array}$ & $\begin{array}{l}\text { Facilitating group discussions, explaining to } \\
\text { groups the task requirements and how to use } \\
\text { visual aid to complete the task }\end{array}$ \\
\hline Keeping the child's attention & $\begin{array}{l}\text { Asking question which links story to daily } \\
\text { lives of pupils in class, instructing child to } \\
\text { participate in class activities, asking questions } \\
\text { to check on child's understanding }\end{array}$ \\
\hline
\end{tabular}

Table 5 Follow-up responses to questions

\begin{tabular}{|c|c|c|c|}
\hline Follow-up responses & $\begin{array}{l}\text { Case studies } \\
\text { (EAL/SLCN case studies in } \\
\text { bold; EAL/LD case studies in } \\
\text { regular font) }\end{array}$ & $\begin{array}{l}\text { EAL/ } \\
\text { SLCN } \\
\text { group }\end{array}$ & $\begin{array}{l}\text { EAL/ } \\
\text { LD } \\
\text { group }\end{array}$ \\
\hline Affirmation & AP1-AP4, CP4, DP1, BP3 & $\checkmark$ & $\checkmark$ \\
\hline Positive reinforcement & DP1 and DP4, CP2 & $\checkmark$ & $\checkmark$ \\
\hline Prompts & CP4, BP3, CP2 & $\checkmark$ & $\checkmark$ \\
\hline Modelling & DP1, CP2 & $\checkmark$ & $\checkmark$ \\
\hline Description to engage the child & DP4 & $\checkmark$ & \\
\hline $\begin{array}{l}\text { Follow-up question: } \\
\text { Decomposition }\end{array}$ & DP1, CP2 & $\checkmark$ & $\checkmark$ \\
\hline Follow-up question: Clarifying & DP1 and DP4, CP2 & $\checkmark$ & $\checkmark$ \\
\hline Follow-up question: Probing & DP4 & $\checkmark$ & \\
\hline $\begin{array}{l}\text { Follow-up question: } \\
\text { Simplification }\end{array}$ & DP4 & $\checkmark$ & \\
\hline $\begin{array}{l}\text { Follow-up question: } \\
\text { Vocabulary }\end{array}$ & CP4 & $\checkmark$ & \\
\hline $\begin{array}{l}\text { Follow-up higher-level } \\
\text { question (justification of } \\
\text { answer) }\end{array}$ & AP2, CP4 & $\checkmark$ & \\
\hline Follow-up closed question & AP2. CP4, DP4 & $\checkmark$ & \\
\hline Negative evaluation & BP3 & & $\checkmark$ \\
\hline Suggestion & CP4 & $\checkmark$ & \\
\hline $\begin{array}{l}\text { Repeating pupil's one-word } \\
\text { answer using a short phrase }\end{array}$ & CP4 & $\checkmark$ & \\
\hline Direct instruction & DP4 & $\checkmark$ & \\
\hline No follow-up response & DP1 and DP4, BP3 & $\checkmark$ & $\checkmark$ \\
\hline $\begin{array}{l}\text { Asking the same question to } \\
\text { another pupil }\end{array}$ & DP1 & $\checkmark$ & \\
\hline
\end{tabular}

